\title{
Increase in Plasma Phospholipid Docosahexaenoic and Eicosapentaenoic Acids as a Reflection of their Intake and Mode of Administration'
}

\author{
C-C. FRANK LIU, SUSAN E. CARLSON, ${ }^{2}$ PHILIP G. RHODES, ${ }^{3}$ VATSALA S. RAO, AND \\ EDWARD F. MEYDRECH \\ Department of Pediatrics, Division of Newborn Medicine and Preventive Medicine, University of Mississippi \\ Medical Center, Jackson, Mississippi
}

\begin{abstract}
The fatty acid, docosahexaenoic acid (DHA, 22:6n-3), is a major constituent of red blood cell phosphatidylethanolamine and phosphatidylserine at birth but declines in all phospholipid classes following preterm delivery unless the diet contains DHA. A bolus of fish oil prevented declines in DHA of red cell phospholipids (phosphatidylethanolamine, phosphatidylcholine, and phosphatidylserine) during 4 to 6 wk of feeding, with red blood cell DHA indistinguishable from that of infants fed human milk. The amount of DHA fed was almost an order of magnitude greater than usually provided by human milk, however, suggesting poor absorption of fish oil by preterm infants. The purpose of these studies was to determine if uptake of fish oil DHA could be improved by dispersion in preterm formula. Since plasma phospholipids rapidly reflect changes in dietary fatty acid composition, DHA uptake was assessed by fatty acid analysis of plasma phosphatidylethanolamine and phosphatidylcholine. All groups receiving fish oil (both bolus and dispersed) demonstrated a rise in plasma phospholipid phosphatidylethanolamine DHA. Infants receiving $11 \mathrm{mg} / \mathrm{kg} /$ day DHA from dispersed fish oil, however, appeared to absorb as much or more as those receiving $71 \mathrm{mg} / \mathrm{kg} / \mathrm{day} \mathrm{DHA}$ in a bolus. The lower intake of DHA provided only $0.2 \%$ of total dietary fatty acids (human milk typically provides 0.1 to $0.3 \%$ ). This study, in conjunction with an earlier report, demonstrates the feasibility of 1) long-term maintenance of red cell membrane DHA by its inclusion in infant formula and 2) DHA maintenance by "physiological" intakes of DHA; i.e. the amount provided by human milk. Both factors are important in order to undertake studies of DHA function in preterm infants without undue concern for their safety. Fatty acids are designated as number of carbons:number of double bonds and family (n-6, derived from linoleic acid; n-3, derived from linolenic acid), thus 22:5n-6 contains 22 carbons, five double bonds, and is derived from linoleic acid. (Pediatr Res 22: 292-296, 1987)
\end{abstract}

Received October 31, 1986; accepted April 8, 1987

Correspondence and reprint requests Susan E. Carlson, Ph.D., Newborn Center, 853 Jefferson Avenue, Room 201, Memphis, TN 38163.

Supported in part by a grant-in-aid from Ross Laboratories, Columbus, $\mathrm{OH}$

'A portion of this study appeared in abstract form in the American. Journal of Clinical Nutrition (1) and was presented at the 1986 meeting of the American Society for Clinical Nutrition in Washington, D.C.

${ }^{2}$ Present address The University of Tennessee, Department of Pediatrics, Newborn Center, 853 Jefferson Avenue, Mcmphis, TN 38163.

${ }^{3}$ Present address Children's Mercy Hospital, Division of Neonatology, 24th at Gillham Road, Kansas City, MO 64108.
Abbreviations

DHA, 22:6n-3-docosahexaenoic acid

EPA, 20:5n-3-eicosapentaenoic acid

PE, phosphatidylethanolamine

PC, phosphatidylcholine

PS, phosphatidylserine

TG, triglyceride

BHT, butylated hydroxytoluene

SAS, statistical analysis system

Both mammalian brain gray matter and retinal membrane ethanolamine phosphoglyceride are enriched highly in docosahexaenoic acid (DHA, 22:6n-3) (1-5), an elongation-desaturation product of linolenic acid $(18: 3 n-3)$. In the human infant most accumulation of DHA in these membranes occurs in the last intrauterine trimester $(6,7)$. Studies undertaken by Clandinin and coworkers $(6,8,9)$ provided evidence that human milk could meet the theoretical needs for brain polyunsaturated fatty acids following premature delivery. A study of red blood cell phospholipids in preterm infants provided evidence that DHA status prior to birth is maintained by maternal/placental transfer, that DHA in human milk does indeed substitute in part for this accumulation, and that preterm infants have a relatively poor ability to convert $18: 3 n-3$ to DHA (2). Other investigators have raised the question of the ability of the neonate to convert both linoleic $(18: 2 n-6)$ and linolenic $(18: 3 n-3)$ acids to the long-chain polyenoates concentrated in nervous tissue $(9,10)$ since humans appear to have a limited ability for $\Delta^{4}$-desaturation (11), the final catalytic step in the formation of $22: 5 n-6$ and $22: 6 n-3$.

No direct evidence is available to evaluate the degree of $d e$ novo synthesis of the 22-carbon polyunsaturates by developing infants. Indirect evidence that $\Delta^{4}$-desaturation is limited in preterm infants is based on the steady decline in membrane DHA following birth early in the third trimester $(2,3)$. Decreases in red blood cell DHA in preterm infants may be indicative of limited DHA accumulation during the period when it normally accumulates in the central nervous system. Studies in the rat show that the DHA content of red blood cell phospholipids is related to those of the central nervous system during development (12). Poor accumulation of DHA during development has been associated with abnormalities in visual acuity and electroretinograms in the rhesus monkey $(13,14)$ and electroretinograms $(15,16)$ and behavior $(17,18)$ in the rat. DHA may be necessary during a specific developmental period as abnormal electroretinograms in rhesus monkeys and rats, respectively, were 
not reversed by later normalization of membrane $D H \wedge$ with a source of dietary I) IA (14. 15). Fividence contradicting a role for $\mathrm{D} H \mathrm{~A}$ in normal vision and retinal response to light has also been reported (19,20)

As noted previously, the small amount of DIIA in human milk $(0.1100 .3 \%$ of total fatty acids) $(21.22)$ is an important source of red blood cell I)HA in developing infants (2, 21). Since many preterm infants do not receive human milk, a fish oil triglyceride highly concentrated in both DHA and I:PA (MaxIPA, R. P. Scherer. Troy, MI) wats administered by orogastric tube $(750 \mathrm{mg} / \mathrm{kg} /$ day $)$. This dose prevented the decline in red blood cell phospholipid DHA (3) with treated infants having red blood cell phospholipid DHA like infants fed human milk $(2,21)$.

The present investigation was designed to determine if uptake of DIIA could be improved by microdispersion of fish oil in preterm formula and consequent administration in multiple daily feedings. Our hypothesis was that microdispersion/multiple feedings would increase uptake compared to bolus fish oil in preterm infants. Since plasma phospholipids rapidly reflect changes in dietary fatty acid composition. DHA uptake was assessed by fatty acid analysis of plasma PE and PC. Triglyceride fatty acids were analyzed also. Infants were fed one of three formulas containing by analysis either $(0,0.2$, or $(0.5 \%$ DHA and 0, 0.34 and $0.8 \%$ E.PA by weight. The fish oil source of $\mathrm{DHA}$ was microdispersed in a formula designed for preterm infants (Similac Special Care, Ross I aboratories, (olumbus. OH) and administered in eight identical daily feedings (study 2). Data from these infants are contrasted with those from infants receiving daily either 6.5 or 2.6 limes the intake of both EPA and DHA in a single bolus of fish oil (study 1 ).

\section{MATERIALS AND METHODS}

Study population. Infants enrolled in these studies weighed less than 150() $\mathrm{g}$ at birth (range 560 to $1440 \mathrm{~g}$ ). All were free of major congenital malformations and disease processes. Most infants received respiratory support for a short interval prior to entering the study with either continuous positive airway pressure or intubation and mechanical ventilation. Red blood cells were administered as necessary to maintain a hematocrit of $40 \%$ in infants until they reached $1500 \mathrm{~g}$. The infants were discharged at approximately $1800 \mathrm{~g}$. A total of 17 infants was recruited for study 2 in April and May of 1986, and all samples were collected by mid-June. Most of these patients were born in March and April 1986. During these 2 months a total of 44 infants weighing less than $1400 \mathrm{~g}$ at birth were admitted to the intensive care unit and survived. One infant enrolled did not complete the 2 wh of feeding because of feeding intolerance resulting in removal of enteral feedings for more than $24 \mathrm{~h}$. This infant received the lower level of fish oil supplementation. Details of the period of enrollment and the number of infants enrolled. lost to the study. and available for enrollment during study 1 have been published (3).

Experimental design. The design of study 1 has been described (3). Infants in study 2 were enrolled after obtaining informed consent from a parent as approved by the Institutional Review Board of the University of Mississippi Medical Center. Study 2 infants were randomly assigned to receive one of three formulas. By calculation from the analysis of the individual components of Similac Special Care and MaxEPA and by gas chromatographic analysis of the sonicated formulas, these three formulas contained $0,0.2$, and $0.5 \%$ of total fatty acids as DHA and 0 . 0.34 , and $0.80 \%$ as EPA, respectively. Blood samples were drawn at () time (enrollment, start of treatment) and after 1.7, and 14 days. The fatty acid composition of plasma phospholipids (PE. $P C)$ and TG was analyzed by gas chromatography after purification of each lipid class and transmethylation of fatty acids with boron trifluoride-methanol.

The design of study 2 differed from study 1 in that a) all infants received the identical preterm formula (Similac Special (are. Ross I aboratories. Columbus. ()H) instead of any of several preterm formulas: h) all infants received $100 \mathrm{kcal} / \mathrm{kg} / \mathrm{dal}$ of Similac Special (are with intake adjusted for weight gain weekly instead of a range of intakes (60) to $120 \mathrm{kcal} / \mathrm{kg} / \mathrm{dar}):(\mathrm{c})$ the daily dose of fish oil was dispersed in formula by ultrasound and administered in eight daily fecdings instead of once daily as a bolus: and (d) all study 2 infants were provided with daily supplementary vitamin F: $(25 \mathrm{IU}$. Aquasol 1 : drops. Armour Pharmaceutical (o.. Kankakee, $11.15[1 /(0.3 \mathrm{ml})$ and vitamin 1) (400 16 . Drisdol-Winthrop-Breon. New York. NY. $8000 \mathrm{ll} !$ $\mathrm{ml}$ in propylene glycol)

Formula preparation. Infants in study 2 received Similac $S_{p} x-$ cial Care (20) kcal/oz) to which cither $250 \mu \mathrm{l}$ of soybean oil (1)"; DHA) or 100 or $250 \mu 1$ of MaxEPA (0.2 and $0.5 \%$, I)HA. respectively) was added to aach $4-(\%$ bottle. These oils were dispersed in the formula with a Sonicator Lltrasonic Processor W375 (Heat Svstems Ultrasonics. Inc.. Farmingdale, WY) using an output control of 7 . a percent cycle of 75 and a 9 -inch tip for four 2()-s intervals. The formula was immersed in ice during sonication. The fatty acid composition of formula prepared in this manner remained homogenous for at least $24 \mathrm{~h}$. vew formula was prepared daily and refrigerated until use. All formulas were fed at $150 \mathrm{ml} / \mathrm{kg} / \mathrm{day}$ and. including the added oils. provided 102.101 , or $102 \mathrm{kcal} / \mathrm{kg} /$ day for the formulas containing (). (0.2. or $0.5 \%$ of dietary fatty acids as I)HA. I)HA and I:PA intakes achieved for these formulas were $($ and 0.11 and 19. and 27 and $49 \mathrm{mg} / \mathrm{kg} / \mathrm{day}$ as compared to 71 and $125 \mathrm{mg} / \mathrm{kg} / \mathrm{day}$ for study 1. These concentrations of fish oil were chosen after a pilot study in which supplemented infants $(n=2)$ received 81 $\mathrm{mg} / \mathrm{kg} /$ day of DHA dispersed in formula. Plasma phospholipid EPA and DHA increased so markedly that the experiment was terminated at five days. Study 2 formulas were designed. therefore. to provide much lower amounts of DHA and I:PA. Formulas provided $0 .(0.2$ and $0.5 \% \mathrm{DH} \wedge$ by weight of total fatty acids. The level of $0.2 \%$ was chosen because it represented the amount of DHA reported in preterm milk to maintain membrane phospholipid DHA (2). DHA was included at at higher concentration $(0.5 \%)$ in the other experimental formula $t)$ compensate for possible limitations in digestion and absorption by preterm infants. All stated DHA and EPA intakes were calculated from analysis of the lot of MaxEPA fed in these studies (9.41" DHA and $16.72 \%$ FPA and the density of MaxEPA $(0.93 \mathrm{~g} / \mathrm{ml})$ and rounded to the nearest mg. [Note: the manufacturer reports MaxEPA to contain 12-14\% DHA and 18-20\% I:PA (weight percent of total fatty acids).] These calculated values differ slightly from those determined using the weight pereent of I)HA and EPA determined in study 2 formulas.

Blood samples. One $\mathrm{ml}$ of blood was drawn from an arm vein and added to F.DTA to prevent coagulation. Plasma was removed after centrifugation at $5^{\circ} \mathrm{C}$ and the red blood cells washed three times with a solution of $0.15 \mathrm{M} \mathrm{NaCl}, 1 \mathrm{mM}$ EIDTA. Both plasma and red blood cells were stored at $-20^{\circ} \mathrm{C}$ in a nitrogen atmosphere until analysis. This was accomplished in 2 to 10 days for plasma from study 2 and the red blood cells from both studies. Plasma samples from infants in study 1 were analyzed after 3 to 4 months of storage.

Preparation and analisis of phospholipid and Th fattly acids. In both studies total lipids in plasma were extracted by the procedure of Dodge and Phillips (23) using chloroform and methanol. Methanol contained $50 \mathrm{mg} / \mathrm{l}$ of $\mathrm{BHT}$ as an antioxidant. The lipid extracts were washed with $0.15 \mathrm{M} \mathrm{KCl}$ according to Folch ef al. (24) and the organic solvent phase vaporized under nitrogen and fractionated by thin layer chromatography [Silica gel $\mathrm{G}$ plates. $10 \times 20 \mathrm{~cm}$ (width $\times$ height), Analtech. Inc.. Newark. DE]. Plasma TG was separated by cluting with hexane:diethyl ether:acetic acid (80:20:1) and migrated with an $R_{i}$ $>0.5$.

Phospholipids remained at the origin during the first elution and were immediately fractionated into individual classes by 
eluting again with chloroform:methanol:acetic acid:water $(60: 40: 8.4: 4.6)$. This solvent system is a slight modification of that of Zail and Pickering (25). The procedures used for identification and isolation of the phospholipid bands (PE, PC) have been published, along with details of the preparation of fatty acid methyl esters (26) and their identification and quantitation by gas liquid chromatography (3). Data are expressed here for only plasma PE DHA and EPA, but detailed information of other plasma fatty acids and red blood cell phospholipid (PE, PC, PS) fatty acids (study 2) may be obtained from the authors. Red blood cell phospholipid analysis from study 1 has been published (3).

Statistical analysis. Fatty acids were analyzed following the multivariate analysis of variance approach of Cole and Grizzle (27) with significant treatment differences explored using the student Newman-Keul's multiple range test. For each fatty acid analyzed, significant treatment, time or time $\times$ treatment interactions were possible. Calculations were performed on the SAS (28) data package.

\section{RESULTS}

Bolus orogastric administration of fish oil (study 1). Infants in study 1 had body weights at birth ranging from 600 to $1440 \mathrm{~g}$ with means $( \pm \mathrm{SD})$ in unsupplemented and supplemented groups of $963 \pm 209$ and $944 \pm 191$, respectively. Infants ranged in age from 10 to 53 days at enrollment with means $( \pm$ SD) of $28 \pm 14$ and $25 \pm 10$ days in the two respective groups. These differences were not significant.

Figure 1 demonstrates graphically the effect of both time and treatment on plasma PE DHA and EPA. Infants receiving preterm formula only had a mean biweekly decline in PE DHA which differed from enrollment values at 4 and $6 \mathrm{wk}(p<0.01)$. With bolus fish oil both PE DHA and EPA increased by 2 wk $(p<0.01)$. The mean for PE DHA and EPA after 2,4 , and 6 wk of supplementation did not differ significantly. Although DHA constituted $\leq 2 \%$ of plasma PC fatty acids and $\leq 0.4 \%$ of

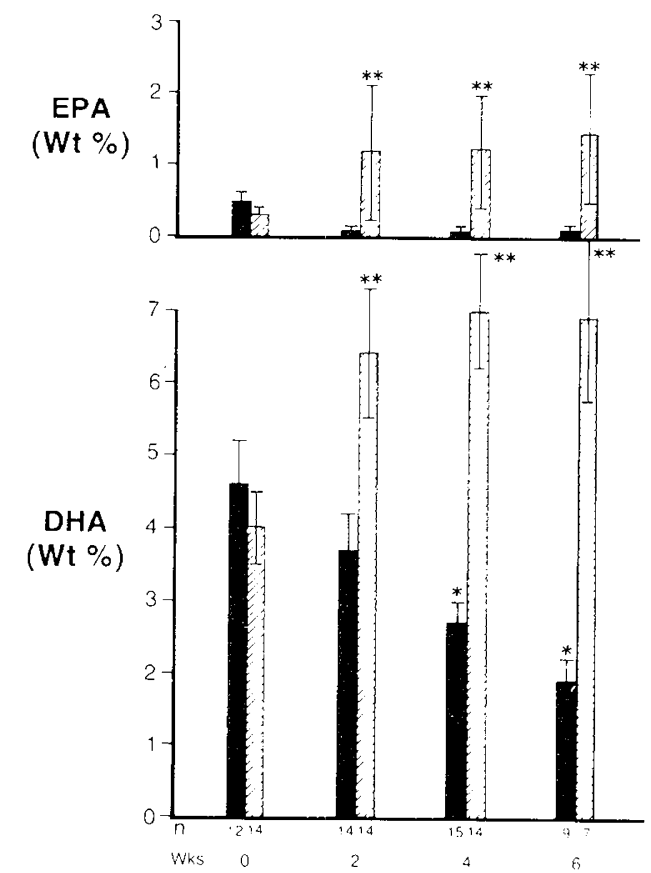

Fig. 1. Study 1. Plasma phosphatidylethanolamine EPA and DHA (weight percent of total fatty acids) at 0 (enrollment), 2, 4, and $6 \mathrm{wk}$ of study. preterm formula only; $\mathbb{Q}$, preterm formula and single daily bolus of fish oil $(750 \mathrm{mg} / \mathrm{kg}$ ) containing approximately $71 \mathrm{mg} / \mathrm{kg}$ DHA and $125 \mathrm{mg}$ EPA. Error bars indicate SEM. Time by treatment, $p<$ $0.0010 .{ }^{*}$ Differs from unsupplemented at enrollment, $p<0.01:{ }^{* *}$ differs from supplemented at enrollment, $p<0.01$. plasma TG fatty acids, the same relative time and treatment effects occurred in these lipid classes $(p<0.01)$ as in PE DHA. Furthermore, as with PE DHA, additional significant increases did not occur beyond $2 \mathrm{wk}$ of fish oil administration. By analysis of variance time $\times$ treatment interactions for EPA $(20: 5 n-3)$ and DHA $(22: 6 n-3)$ were significant in plasma phospholipids (PE, PC, $p<0.901)$ and TG $(p<0.02)$.

Other than DHA and EPA, only 22:5n-6 showed a highly significant effect of treatment. Lower values were observed in both PE $(p<0.0001)$ and PC $(p<0.0002)$ in supplemented compared to unsupplemented infants. After four weeks PE arachidonate $(20: 4 n-6)$ showed a less significant $(p<0.04)$ treatment effect. The weight percent in unsupplemented declined from 17 to $14.2 \%$ while in supplemented infants the decline was from 13.4 to $12.2 \%$.

Several fatty acids in phospholipids changed significantly with time (i.e. independent of treatment). In two of the three (PE, PC, $\mathrm{TG})$ plasma lipid fractions a significant increase in linoleic acid $(18: 2 \mathrm{n}-6)(p<0.001)$ and decrease in 20:4n-6 $(p<0.05)$ occurred with time. In addition, plasma PC 16:0 ( $p<0.004), 20: 3 n-6$ ( $p$ $<0.006)$, and $22: 5 n-6(p<0.003)$ decreased significantly with time while 18:0 $(p<0.001)$ and 22:5n-3 $(p<0.05)$ increased with time. Despite the decline in DHA in unsupplemented infants, $22: 5 \mathrm{n}-6$ did not increase as would have been expected with normal $\Delta^{4}$-desaturase activity.

Administration of microdispersed fish oil (study 2). Infants in study 2 had body weights at birth ranging from 560 to $1390 \mathrm{~g}$ with means $( \pm \mathrm{SD})$ in unsupplemented $(n=6)$, low fish oilsupplemented $(11 \mathrm{mg} / \mathrm{kg} /$ day DHA, $0.2 \%$ of fatty acids, $n=4)$, and high fish oil-supplemented $(27 \mathrm{mg} / \mathrm{kg} /$ day DHA, $0.5 \%$ of total fatty acids, $n=6$ ) of $974 \pm 300,932 \pm 314$, and $938 \pm 98$ g. At enrollment infants ranged in age from 14 to 49 days except for one infant in the high supplement group who was 71 days old. The mean age at enrollment was $29 \pm 11(18-47)$ days, 28 $\pm 11(21-44)$ days, and $41 \pm 21(14-49,71)$ days for the respective groups. These differences were not significant.

Figure 2 indicates the effects of time and the two levels of fish oil supplementation on plasma PE DHA and EPA. Only the formula containing $0.2 \%$ DHA at 14 days differed significantly
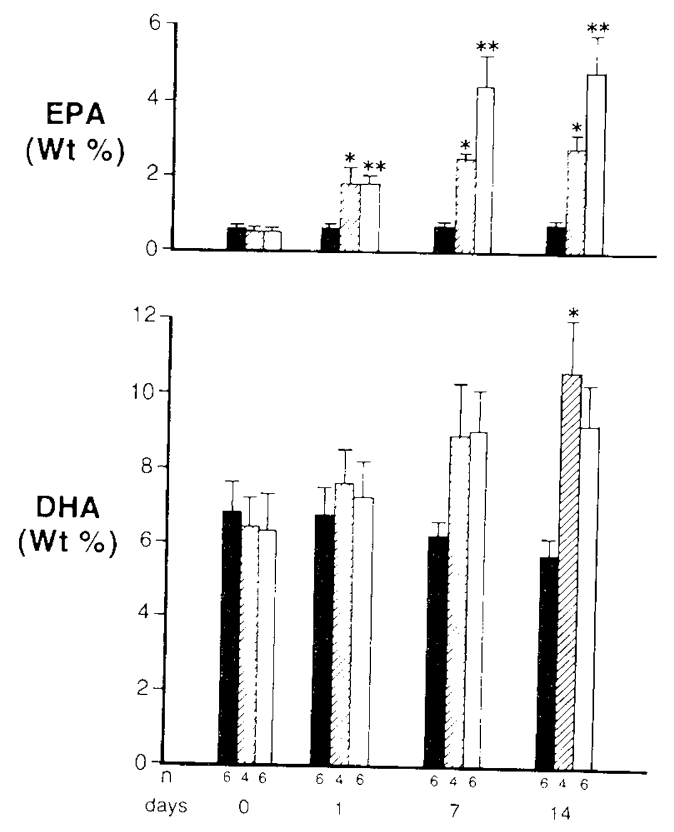

Fig. 2. Study 2. Plasma phosphatidylethanolamine EPA and DHA weight percent of total fatty acids) at 0 (enrollment), 1, 7, and 14 days. Formula with $0 \%$ DHA $\mathbf{m}: 0.2 \%$ DHA $\mathbb{\$}: 0.5 \%$ DHA $\square$. Error bars indicate SEM. Time by treatment, $p<0.02 .{ }^{*}$ Differs from $0.2 \%$ DHA at enroliment, $p<0.02$; ${ }^{* *}$ differs from $0.5 \%$ DHA at enrollment, $p<$ 0.01 . 
from enrollment using the Student's / test although the orerall time $x$ treatment effect on PF: I)HIA was significant $(p<0.02)$. Furthermore, supplemented (both 0.2 and $0.5 \%$ I)HA) infants had significantly greater PI: I)HA compared to unsupplemented infants after seven and 14 days of feeding $(p<(1.05)$. The two doses of DHA (0.2 or (0.5\%) resulted in similar plasma PE I HIA

IEP had already increased signilicantly hy $24 \mathrm{~h}$ in the 1 wo fish oil-supplemented groups. PI: EPA in fish oil-supplemented infants differed significantly from () (enrollment) at 1.7 . and 14 days $(p<0.01)$. Furthermore. PI IEPA was significantly higher in infants receiving the higher compared to the lower dose of tish oil at both 7 and 14 days $(p<0.0 .5)$.

The only other time $\times$ treatment effect which was significant in study 2 was $P(20) 4 n-6(\rho)<0.05)$. $P\left(C^{\prime} 20\right): 4 n-6$ decreased from $8.4106 .9 \%$ in infants receiving the higher kevel of tish oil supplementation over 14 days bul did not change in infants without supplementation (8.9 $108.7 \%$ ) or receiving the low level of supplementation $(8.2$ to $8.2 \%)$.

Several other fatty acids changed significantly with time irrespective of treatment: 22:5n-3 increased in PI: PC and $\mathrm{IC}(i)$ $<0.00(0) 2$. $0.0(0.3$. and $0.0(02)$. 18:1 decreased in these same respective lipids $(p<<0.04$. 0.002 , and $(0.003)$. and $22.5 n-6$ decreased in PI $(p<0,(0) 2)$ and $P\left({ }^{\prime}(p<0.0(0))\right.$. These changes were not obviously altered by treatment except in the case of 22:5n-3 which appeared to increase more in the supplemented groups.

Study 1 infants received daily $71 \mathrm{mg} / \mathrm{kg} /$ day of $\mathrm{D}) \mathrm{l} / \mathrm{A}$ and 125 $\mathrm{mg} / \mathrm{kg} /$ day of $\mathrm{l} \mathrm{P} \wedge$. This amounted to 6.5 and 2 .6 times as much of each fatty acid as provided by the formula containing 0.2 and (0.5\% DUA fed in study 2. I)espite the much lower intakes in study 2. the difference between PE B IIA of unsupplemented and supplemented infants was as great or greater after 14 days of feeding: $2.8 \%$ (study 1$)$ and 5.0 and $3.5 \%(0.2$ and $0.5 \%$ D) 1 A. study 2) (Fig. 3). Similarly. the difference in PI: I:PA was 1.3\% in study 1 compared 102.1 and $3.7 \%$ in study 2 (Fïg. 3). In PC and T( 3 , study 2 infants also had DHA and I:PA as high or

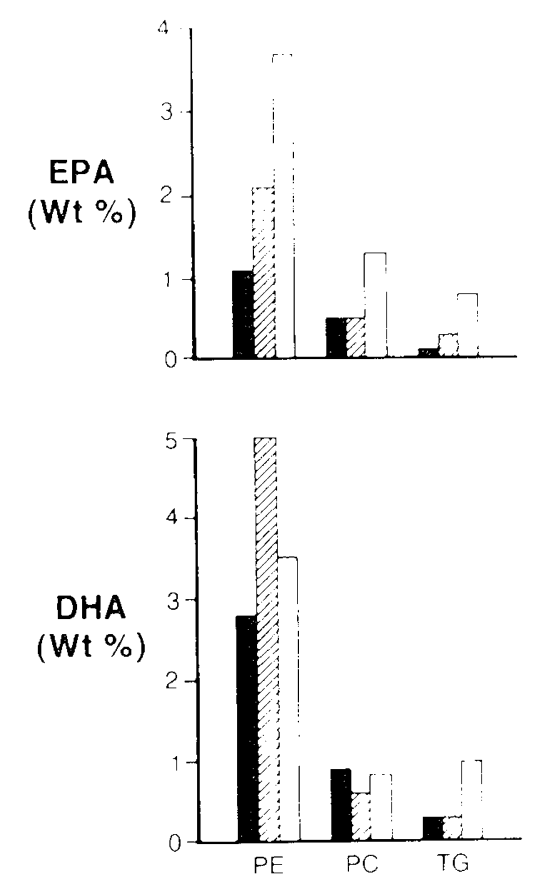

Fig. 3. Increase ( $\bar{X}$ supplemented - $X$ unsupplemented $)$ in plasma IEP and I JIA with lish oil supplementation after 14 days of treament. - $125 \mathrm{mg} / \mathrm{kg} /$ day $\mathrm{LPA}$ and $71 \mathrm{mg} / \mathrm{kg} /$ day I) IA . once daily bolus (study

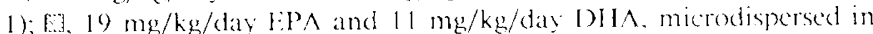
formula and administered in 8 feedings/d (study 2): [־]. $49 \mathrm{mg} / \mathrm{kg} / \mathrm{day}$ EPA and $27 \mathrm{mg} / \mathrm{kg} /$ day I IHA, microdispersed in formula and administered in eight feedings/day (study 2). higher than study I infants (lig. 3). b) Figure 3 also graphically demonstrates the enrichment of plasma PI $>P C^{\circ}>I^{\prime}(i$ with I)HA and EPA following lish oil administration.

Red blood eell phospholipids of all study 2 infants were analyed over the course of the If-dat stud although previous experience suggested that tratment effects would not oceur by 14 dass (3). Vewertheless. Pl: and P( I:P: (20):n-3) did demonstrate a significant time $\times$ treatment interation $(p)<0 .(1)$ and $<0$ ()4. respectively) in this short period of time. Furthermore. in at least two of the phospholipid classes analyed (P'I. P' ${ }^{\circ}$. and PS). significant increases in $18: 2 n-6$ and decreases in $2(0)-4 n-6$ and 22:5n-6 occurred with time. The effects of tish oil supplementat tion on red blood cell phospholipid DHA and I:PS in studs 1 have been published ( 3$)$.

\section{I) $15(\operatorname{sisio})$}

The results of plasma phespholipid hatty acid analysis are presented for preterm infants following supplementation with fisin oil highly concentrated in both DHA and I:PA. The primall? purpose of these studies was to determine if uptake of D H. I and FPA could be improved by microdispersion of tish oil in preterm formula and consequent administrattion in multiple date fecedings (stud 2) compared to a single daily orogastric bolus aldministered with formula (study 1). Since plasma phospholipids rapidly reflect changes in dietary fatty acto composition. D)H1 and I:PA uptake were assessed be fatte acid analesis of plasma Pl: $P(C$ and $T(j$.

The data suggest that the amount of fish oil absorbed was as greal or greater in study 2 as in study I infants despite much lower absolute intakes in study 2: a) The increase in I)HA and I:PA after 2 wh of supplementation was as great or greater in study 2 compared to study 1 infints (Fig. 3). b) Red bleod cell $P F$ and $P\left(C^{\prime}\right.$ EPA demonstrated a significant time hy treatment effect at 14 dass in study 2 but not until 4 wh in study 1 (3) despite significant increases in plasma I:PA (and I)HA) by 2 wh (Fï. 1). Plasma PF D)HA increased by 2 wh and. thereatter. remained unchanged during 2 to 6 wh of continuous supplementation (Fig. 1). While red blood cell PI: I)HA remained high during this same period (3). Together these studies suggest the feasibility of long-term maintenance of red eell membrane D HA by its inclusion in infant formula.

Since intakes of tish oil from the formulas fed in study 2 wero only $15 \%,(0.2 \%$ D)HA) and $38 \%(0.5 \%$, D H HA) of those in study 1. the proportion of tish oil absorbed must have been increased dramatically in the second study. Preterm infants are recennised to have low kevels of pancreatic lipase and bile salts which can limit their ability to digest and absorb dietary lat. I Dispersion of the fat in microparticles mas have enhanced the efficience of lipase and bile salts which were available. Roy e/ al. (29). in what may be an analogous situation. demonstrated dramatically improved lipid digestion when rats deprived of salivary lipase were fed lipids microdispersed by ultrasonication. The proportional uptake of fish oil fatty acids mal have been improved also by multiple rather than single dail addition(s) to the diet.

When comparing the two kevels of supplementary lish oil in

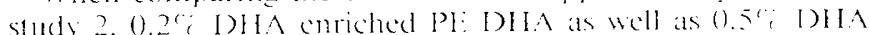
Fortuitously. ().2\%; D)HA is in the range of DHA provided by buman milk $[(0.1-() .3 \%(21.22)]$. The lower lesel of 1$)$ HI supplementation also produced a smaller enrichment of PI I:P and did not decrease plasma phospholipid arachidence acid Potent metabolic effects have been shown to occur als a result of dietary changes which alter the ratio of arachidonic acid $\quad$ (1) I:P 1 Decreases in this ratio decreased stuthesis of prostaglandin l: and thromboxane $A$. (30). 31). Fish oils enriched in I:P'A and I)HA fed at levels (g/ $\mathrm{kg} / \mathrm{day}$ ) onle slightly higher than recerved by our study 2 infants administered $0.5 \%$ D) 1 is reduced human leukotriene $B_{4}$ generation and the chemotactic response of neutrophils to leukotriene $B_{\text {in }}$ by 50 to 70$)^{\prime} ;$ (.32).

Ideally. DHA included in formula at a physiological concen- 
tration could provide long-term maintenance of membrane phospholipid DHA in preterm infants. Long-term studies of DHA function in preterm infants could then be undertaken without undue concern for infants' safety. Measurement of plasma lipid DHA after bolus administration of fish oil, combined with earlier studies of membrane phospholipid DHA in these same infants (3), indicate levels of plasma DHA which prevent declines in membrane phospholipid DHA. Dispersion of fish oil in formula produced equivalent or greater elevations in plasma lipid DHA. Together these observations suggest that declines in membrane phospholipid DHA following preterm delivery may be prevented by prolonged consumption of DHA in amounts typically consumed by infants fed human milk.

Our hypothesis is that preterm infants may require supplemental DHA for normal functional development of the central nervous system and retina. If lesions exist due to inability of the newborn to synthesize DHA from dietary precursors, preterm infants would likely be more vulnerable than term infants. Accordingly, we have undertaken studies in preterm infants with the goal of measuring development of visual acuity in supplemented and unsupplemented infants during infancy.

Acknowledgment. MaxEPA was supplied by R. P. Scherer Corporation, Troy, MI.

\section{REFERENCES}

1. Carlson SE, Rhodes PG, Rao VS 1986 Accumulation of docosahexaenoic and cicosapentaenoic acids in plasma lipids following fish oil administration to preterm infants. Am J Clin Nutr 43:684(abstr)

2. Carlson SE, Rhodes PG, Ferguson MG 1986 Docosahexaenoic acid status of preterm infants at birth and following feeding with human milk or formula. Am J Clin Nutr 44:798-804

3. Carlson SE, Rhodes PG. Rao VS, Goldgar DE 1987 Effect of fish oil supplementation on the omega- 3 fatty acid content of red blood cell membranes in preterm infants. Pediatr Res 21:507-510

4. O'Brien JS. Fillerup DL, Mean JF 1964 Quantification of fatty acids and fatty aldehyde composition of ethanolamine, choline and serine glycerophosphatides in human cerebral gray and white matter. J Lipid Res 5:329-330

5. Anderson RE 1970 Lipids of ocular tissues. IV. A comparison of the phospholipids from the retina of six mammalian species. Exp Eye Res 10:339-344

6. Clandinin MT, Chappell JE, Leong S, Heim T. Swyer PR, Chance GW 1980 Intrauterine fatty acid accretion rates in human brain: implications for fatty acid requirements. Early Hum Dev 4:121-129

7. Svennerholm I, 1968 Distribution and fatty acid composition of phosphoglycerides in normal human brain. J Lipid Res 9:570-579

8. Clandinin MT, Chappell JE, Heim T, Swyer PR, Chance GW 1981 Fatty acid utilization in perinatal de novo synthesis of tissues. Early Hum Dev 5:355366

9. Clandinin MT, Chappell JE, Heim T 1981 Do low weight infants require nutrition with chain elongation-desaturation products of essential fatty acids? Prog Lipid Res 20:901-904

10. Crawford $M A$, Sinclair AJ 1972 Nutritional influences in the evolution of mammalian brain. In: Elliot K, Knight $J$ (eds) Lipids, Malnutrition and the Developing Brain. Ciba Foundation Symposium. Elsevier, Amsterdam, pp
$267-292$

11. Crawford MA 1976 Lipids and development of the human brain. Biochem Soc Trans 4:231-233.

12. Carlson SE, Carver JD, House SG 1986 High fat diets varying in ratios of polyunsaturated to saturated fatty acid and linoleic to linolenic acid: a comparison of rat neural and red cell membrane phospholipids. J Nutr 116:718-725

13. Neuringer M, Connor WE, Petten CV, Barstad L 1984 Dietary omega-3 fatty acid deficiency and visual loss in infant rhesus monkeys. $J$ Clin Invest 73:272-276

14. Neuringer M, Connor WE, Luck SL 1986 Omega-3 fatty acid deficiency in rhesus monkeys: Depletion of retinal docosahexaenoic acid and abnormal electroretinograms. Am J Clin Nutr 43:706(abstr)

15. Benolken RN, Anderson RE, Wheeler TG 1973 Membrane fatty acids associated with the electrical response in visual excitation. Science 182:1253-1254

16. Wheeler TG, Benolken RM, Anderson RE 1975 Visual membrane: Specificity of fatty acid precursors for the electrical response to illumination. Science 188:1312-1314

17. Lamptey MS, Walker BL 1976 A possible essential role for dietary linolenic acid in the development of the young rat. J Nutr 106:86-93

18. Yamamcto N, Saitoh M, Moriuchi A, Nomura M, Okuyama H 1987 Effect of dietary alpha-linolenate/linoleate balance on brain lipid compositions and learning ability of rats. J Lipid Res 28:144-151

19. Leat WMF, Davidson K 1985 The guinea pig as an animal model in the study of linolenic acid metabolism. XIII International Congress of Nutrition. Brighton, England, p 104 (abstr)

20. Cho ES, Kolder HE, Wertz PE, Downing DT 1985 Electroretinography and retinal phosphatidylcholine fatty acids in W3 fatty acid deficient rat. XIII International Congress of Nutrition. Brighton, England, p 105 (abstr)

21. Putnam JC, Carlson SE, DeVoe PW, Barness LA 1982 The effect of variations in dictary fatty acids of the fatty acid composition of erythrocyte phosphatidylcholine and phosphatidylethanolamine in human infants. Am J Clin Nutr 36:106-114

22. Harris WS, Connor WE. Lindsey S 1984 Will dietary w-3 fatty acids change the composition of human milk. Am J Clin Nutr 40:780-785

23. Dodge JT, Phillips GB 1967 Composition of phospholipids and phospholipid fatty acids and aldehydes in human red cells. J Lipid Res 8:667-675

24. Folch J, Lees M. Stanley GHS 1957 A simple method for the isolation and purification of total lipids from animal tissues. J Biol Chem 226:497-509

25. Zail SS, Pickering A 1979 Fatty acid composition of erythrocytes in hereditary spherocytosis. J Haematol 42:399-402

26. Morrison WR, Smith LM 1964 Preparation of fatty acid methyl esters and dimethylacetals. J Lipid Res 5:600-608

27. Cole JWL. Grizzle JE 1966 Applications of multivariate analysis of variance to repeated measures experiments. Biometrics 22:810-828

28. Barr AJ, Goodnight JH 197 I Statistical Analysis System. North Carolina State University, Raleigh, NC

29. Roy CC. Roulet M, Lefebvre D, Chartrand L, Lepage G, Fournier LA 1979 The role of gastric lipolysis on fat absorption and bile acid metabolism in the rat. Lipids 14:811-815

30. Croft KD. Codde JP, Barden A, Vandongen R, Beilen LJ 1985 Onset of changes in phospholipid fatty acid composition and prostaglandin synthesis following dietary manipulation with $n-6$ and $n-3$ fatty acid in the rat. Biochim Biophys Acta 834:316-323

31. Moncado S, Vane JR 1979 Arachidonic acid metabolites and the interactions between platelets and blood vessel walls. N Engl J Med 300:1142-1174

32. Lee TH. Hoover RL, Williams JD, Sperling RI, Ravalise J, Spur BW, Robinson DR, Corey EJ, Lewis RA. Quester KF 1985 Effect of dietary enrichment with eicosapentaenoic and docosahexaenoic acids on in vitro neutrophil and monocyte leukotriene generation and neutrophil function. N Engl J Med $312: 1217-1224$ 